\title{
A mídia em meio às 'emergências' do vírus Zika: questões para o campo da comunicação e saúde
}

\author{
The media among the Zika virus 'emergencies": issues for the \\ communication and health field
}

\section{Los medios de comunicación entre las 'emergencias' del virus Zika: preguntas para el campo de la comunicación y salud}

\author{
Raquel Aguiar | raquelaguiar@ioc.fiocruz.br \\ Fundação Oswaldo Cruz, Instituto Oswaldo Cruz (IOC), Assessoria de comunicação. \\ Instituto de Comunicação e Informação Científica e Tecnológica em Saúde (Icict), Programa de Pós-Graduação em \\ Informação e Comunicação em Saúde (PPGICS). Rio de Janeiro, Brasil.
}

\section{Inesita Soares Araujo | inesita.araujo@icict.fiocruz.br \\ Fundação Oswaldo Cruz, Instituto de Comunicação e Informação Científica e Tecnológica em Saúde (Icict), Laboratório de Comunicação e Saúde, Programa de Pós-Graduação em Informação e Comunicação em Saúde (PPGICS). Rio de Janeiro, Brasil.}

\section{Resumo}

Típico caso de um vírus emergente, o Zika havia circulado de forma restrita quando chegou ao Brasil, onde acabaria por se tornar parte de uma emergência em saúde pública e um tema com fortíssima presença nos meios de comunicação em 2015. Este artigo baseia-se em um trabalho realizado no contexto do Observatório Saúde na Mídia, no qual traçamos uma linha do tempo com os principais pontos da escalada de atenção sobre o vírus Zika na mídia brasileira em 2015, incluindo a cobertura midiática e os anúncios oficiais. Confrontamos essa linha do tempo com uma análise de capas de nove jornais impressos publicados nos meses de novembro e dezembro de 2015, período em que o Ministério da Saúde admitiu a possível correlação do vírus com o aumento de casos de microcefalia no país. Enfocamos referências a medo e risco e propusemos algumas reflexões sobre a relação entre a comunicação e a saúde.

Palavras-chave: Comunicação e saúde; Imprensa; Vírus Zika; Epidemias.

\begin{abstract}
Typical case of an emerging virus, Zika had circulated in a limited extent when it arrived in Brazil, where would become part of a public health emergency and a theme with very strong presence in the media in 2015. In this article, based on a work prepared in the context of the Health in the Media Observatory, we draw a timeline that seeks to outline the main points of attention on the Zika virus in Brazilian media in 2015, including media coverage and official announcements. This timeline was confronted with the analysis of covers from nine Brazilian newspapers, published in November and December 2015, when the Brazilian Ministry of Health admited a possible correlation between the Zika virus and the increase in microcephaly cases. We focus on references to fear and risk and propose some reflections on the relationship between communication and health.
\end{abstract}

Keywords: Comunication and health; Press; Zika virus; Epidemics. 


\section{Resumen}

Caso típico de un virus emergente, el Zika había circulado de forma limitada cuando llegó a Brasil, donde se convertiría en parte de una emergencia de salud pública y un tema con presencia muy fuerte en los medios de comunicación en 2015. En este artículo, basado en trabajo realizado en el marco del Observatorio de la Salud en los Medios de Comunicación, dibujamos una línea de tiempo que busca delinear los principales puntos de atención sobre el virus Zika en medios brasileños en 2015, incluyendo la cobertura de los medios de comunicación y los anuncios oficiales. Esta linea de tiempo fue confrontada con el análisis de las portadas de nueve periódicos impresos en noviembre y diciembre de 2015, período en el cual el Ministerio de Salud de Brasil reconoció la posible correlación del virus con el aumento de los casos de microcefalia en el país. Enfocamos referencias a miedo y riesgoy y planteamos algunas reflexiones sobre la relación entre comunicación y salud.

Palabras clave: Comunicación y salud; Prensa; Vírus Zika; Epidemias.

\section{Contribuição dos autores:}

Concepção e desenho do estudo, aquisição e análise dos dados e redação do manuscrito: Raquel Aguiar Redação do manuscrito e revisão crítica do conteúdo intelectual: Inesita Araujo

Declaração de conflito de interesses: As autoras declaram que não há qualquer conflito de interesses relacionado à produção e circulação do artigo.

Fontes de financiamentos: A pesquisa não contou com fontes específicas de financiamento.

Considerações éticas: Tratando-se de uma análise de matérias publicadas por mídia de grande circulação e de documentos disponíveis no site do Ministério da Saúde, este trabalho não necessitou ser submetido previamente a conselho de ética.

Agradecimento/Contribuições adicionais: Max Gomes, estudante de jornalismo e estagiário do Instituto Oswaldo Cruz (IOC/ Fiocruz), pelo excelente apoio na fase de levantamento, coleta e organização do material para análise.

Histórico do artigo: Submetido: 1.mar.2016 | Aceito: 3.mar.2016 | Publicado: 31.mar.2016

Apresentação anterior: VideoSaúde Distribuidora da Fiocruz. Aula de abertura do curso de especialização em comunicação e saúde [Internet]. 2016. [citado 16 mar 2016]. Disponível em: https://youtu.be/H3XgtQTZJXQ

Licença: CC BY-NC atribuição não comercial. Com essa licença é permitido acessar, baixar (download), copiar, imprimir, compartilhar, reutilizar e distribuir os artigos, desde que para uso não comercial e com a citação da fonte, conferindo os devidos créditos de autoria e menção à Reciis. Nesses casos, nenhuma permissão é necessária por parte dos autores ou dos editores. 
O vírus Zika havia circulado de forma muito restrita quando chegou ao Brasil, onde acabaria por se tornar parte de uma emergência em saúde pública e um tema com fortíssima presença nos meios de comunicação em 2015. O grande interesse da mídia está especialmente relacionado à possível relação do vírus com o crescimento dos casos de microcefalia em bebês, além da associação com outras doenças, como a síndrome de Guillain-Barré, uma doença autoimune neurológica que pode estar associada a infecções.

As situações extremas, como essa epidemia, exacerbam e tornam mais evidentes questões que já são objeto de atenção e preocupação. O vírus Zika, assim como o HIV e a dengue foram um dia, é um típico caso de vírus emergente, que surge em locais onde anteriormente não existia. Sua introdução e seus impactos no país são uma boa oportunidade para observar a relação entre a mídia e a saúde. Embora "mídia" seja um termo que abrange muitos meios de comunicação, aqui nos reportamos apenas à mídia impressa, mais especificamente aos jornais de grande circulação.

\section{Objetivos}

O trabalho em que se baseia este artigo foi desenvolvido no contexto do Observatório Saúde na Mídia, uma iniciativa do Laboratório de Comunicação e Saúde do Instituto de Comunicação e Informação Científica e Tecnológica em Saúde (Icict/Fiocruz).

Estabelecemos três objetivos. O primeiro foi circunscrever e delinear a cobertura midiática sobre o vírus Zika e seus desdobramentos, de maneira articulada com os anúncios oficiais sobre o tema. Para tanto, traçamos uma linha do tempo, mapeando os principais pontos de atenção na escalada das emergências do vírus em 2015, sempre correlacionando mídia e governo. O período foi escolhido por corresponder à admissão pelo Ministério da Saúde (MS) da possível correlação do vírus Zika com o aumento de casos de microcefalia no país. O segundo objetivo foi identificar modos específicos do dizer midiático sobre o tema, motivo pelo qual procedemos a uma análise de capas de jornais, nos meses de novembro e dezembro de 2015. O terceiro objetivo foi refletir sobre a relação entre a mídia e a saúde, de forma mais ampla entre comunicação e saúde, a partir das especificidades da epidemia do vírus Zika e seu principal desdobramento, a epidemia de microcefalia, que concretizamos propondo nove temas de reflexão.

\section{Metodologia}

Para a elaboração da linha do tempo com os principais pontos de atenção sobre o vírus Zika na mídia brasileira em 2015, recorremos à leitura do acervo de notícias coletadas pelo Observatório Saúde na Mídia e pelo monitoramento de informações do Serviço de Jornalismo e Comunicação do Instituto Oswaldo Cruz (IOC/Fiocruz) sobre vírus Zika e sobre microcefalia. Simultaneamente, realizamos um levantamento no website do Ministério da Saúde (MS), por meio do mecanismo de busca daquele site, no intuito de identificar anúncios oficiais sobre o tema. As buscas em questão foram dos termos "Zika" e "microcefalia".

Para a análise das capas de jornais impressos, selecionamos nove veículos brasileiros. Foram considerados os seis jornais diários de maior circulação no país, de acordo com a Associação Nacional de Jornais (ANJ) ${ }^{1}$, aos quais somamos os jornais de maior circulação na Bahia, Paraíba e Pernambuco, estados que concentraram o maior número de casos de microcefalia no país em 2015, de acordo com o boletim epidemiológico do MS publicado em 29 de dezembro de 2015. Nos casos da Bahia e de Pernambuco, foram selecionados os jornais indicados pela ANJ. Como não há jornais da Paraíba no levantamento da entidade, recorremos aos dados do portfólio de vendas de espaços publicitários do website Meio \& Mensagem². Desta forma, foram considerados na análise os seguintes jornais diários: Correio (BA); Correio da Paraíba (PB); Extra (RJ); Folha de S.Paulo (SP); Jornal do Commercio (PE); O Estado de São Paulo (SP); O Globo (RJ); Super Notícia (MG) e Zero Hora (RS). 
Escolhemos analisar as capas de jornais por refletirem os assuntos de destaque em cada edição. A presença na capa é, pois, um indicador de relevância. Tendo em vista que a admissão pelo MS de possível correlação entre o vírus Zika e os casos de microcefalia ocorreu em novembro, consideramos na análise os meses de novembro e dezembro de 2015. Foram consideradas as capas que continham pelo menos um dos seguintes termos: Zika, microcefalia, dengue, chikungunya e Aedes aegypti. Nesse conjunto, foram buscadas referências explícitas a medo e a risco, numa aproximação preliminar ao tema, que abre espaço para investimentos posteriores e aprofundados de análise.

A ocorrência de notícias sobre o tema nas capas de jornais foi correlacionada aos principais fatos da linha do tempo por meio de uma ilustração gráfica, com sinalização das ocorrências correspondentes aos jornais publicados nos estados com maior número de casos de microcefalia, sendo também sinalizadas as referências a medo e risco.

\section{Linha do tempo: o vírus Zika na mídia brasileira em 2015}

O vírus Zika tem sido objeto de controvérsia desde sua chegada ao país. Os relatos científicos situam os primeiros casos do vírus no início de 2015 em Natal, no Rio Grande do Norte³, e em Camaçari, na Bahia ${ }^{4}$. Em março, começaram a surgir menções na mídia, quando se falava sobre "uma doença ainda sem diagnóstico”. Em matéria publicada na época, o diretor da Vigilância Epidemiológica de Camaçari afirmou que, embora ainda não houvesse sido identificada, a doença "tem evolução benigna e não resulta em nenhum outro problema à saúde". No dia seguinte, a "doença ainda sem diagnóstico" seria tratada como "a doença misteriosa de Camaçari”.

No final de abril, a "doença com manchas vermelhas" era alvo da imprensa na Paraíba, sugerindo que "a primeira suspeita é de que a doença seja um novo tipo de dengue”. Em 29 de abril, a Secretaria de Vigilância em Saúde do MS admitiu que, desde fevereiro, monitorava casos de uma "doença exantemática" no Nordeste. Na ocasião, foi indicado que "as principais hipóteses consideradas nas investigações são: dengue, rubéola, parvovírus B19, chikungunya e sarampo, além de outros arbovírus e enterovírus". Nota-se, portanto, que o vírus Zika não é especificado. Na mesma data, a Universidade Federal da Bahia informou ter identificado o vírus em amostras de pacientes do estado9. O descompasso não passou despercebido pela mídia, como pode ser notado em notícia do Jornal do Commercio, de Pernambuco, em 30 de abril, que apontou que o ministro da Saúde "não quis falar" sobre o vírus Zika durante uma entrevista coletiva convocada sobre outro tema, na qual disse aos repórteres: "vamos fazer uma coletiva sobre o assunto na próxima semana"

O MSadmitiu a "circulação" do vírus Zika no país apenas em 14 de maio"1. Vale observar que, do ponto de vista da saúde pública, a admissão da circulação viral é mais ampla do que a admissão de ocorrência de casos isolados. Soma-se a isto o fato de que quem passou a se pronunciar foi o MS, e não mais uma de suas secretarias, indicando claramente uma escalada na hierarquia, o que denota o salto de importância que o tema adquiriu naquele momento.

Inicialmente, a doença foi considerada "benigna" pelo MS, como notamos nas falas do Ministro da Saúde na época, Arthur Chioro: O zika vírus não nos preocupa. Trata-se de uma doença benigna que tem uma evolução para cura. A febre é baixa, o maior incômodo é o prurido, manchas vermelhas. Requer muito pouco acesso dos pacientes ao prontos-socorros e serviços médicos. Toda a nossa preocupação é com a dengue, porque dengue mata. ${ }^{12}$

É preciso deixar claro que essa não é nossa preocupação. Estamos preocupados com a dengue. ${ }^{13}$

Em julho, começam a surgir notícias comentando o aumento no Nordeste de casos da síndrome de Guillain-Barré. Naquele momento, o discurso do MS sobre a possível relação da síndrome com o vírus Zika passou a ganhar abordagens diferentes na mídia. No jornal $A$ Tarde, da Bahia, foi apontado que "o 
Ministério da Saúde divulgou uma nota em seu site segundo a qual foi identificada uma correlação da doença com a Zika, principalmente em áreas onde também há infestação de dengue"14. Já o jornal Folha de S.Paulo assinalou que "segundo o Ministério da Saúde, ainda não há nenhuma comprovação científica da relação entre a síndrome Guillain-Barré e as três doenças que têm como vetor o mosquito Aedes aegypti" A admissão da possível correlação seria anunciada oficialmente pelo MS no início de dezembro.

O tema da microcefalia ganha espaço no âmbito médico em outubro. Um comunicado aponta que especialistas de Pernambuco e do Rio Grande do Norte estavam notando o aumento dos casos de microcefalia nas maternidades da região metropolitana ${ }^{16}$. $\mathrm{O}$ documento sugere uma possível correlação com o vírus Zika. No final de outubro, durante o IV Congresso do Centro-Oeste de Doenças Infecciosas, Emergentes, Reemergentes e Negligenciadas, o pesquisador Kleber Luz, da Universidade Federal do Rio Grande do Norte, que também assina o documento mencionado anteriormente, sugere durante palestra a correlação entre o aumento de casos de microcefalia e o vírus Zika. Apenas uma notícia sobre o anúncio foi localizada em nosso levantamento, publicada no website do governo do Estado do Mato Grosso do Sul ${ }^{17}$.

Na mídia, as notícias sobre o aumento de casos de microcefalia começam a ser notadas na primeira semana de novembro, em jornais de Pernambuco e da Paraíba, com a sugestão de uma possível associação com o vírus Zika. Em notícia de 4 de novembro, o Jornal do Commércio aponta que a notificação de casos de microcefalia se tornou obrigatória em Pernambuco, com destaque para a hipótese de correlação com dengue, chikungunya ou, em especial, o vírus Zika: Apesar de infecções congênitas entrarem na lista de hipóteses que podem explicar o aumento na incidência da microcefalia, especialistas acreditam que outro agente esteja por trás da atual situação no Estado e investigam uma possível relação entre os casos com a infecção pelos vírus da dengue, chicungunha e zika durante a gestação. ${ }^{18}$

Já a notícia de 7 de novembro, publicada no Jornal da Paraíba, fala de um "aumento até agora inexplicável do número de casos de bebê com microcefalia”, indicando que a Secretaria de Saúde de Campina Grande "avalia a possibilidade do problema estar ligado a casos de gestantes que foram atingidas pelo Zika Vírus"19.

Em 11 de novembro, o Jornal do Commercio publicou matéria de capa sobre microcefalia, o que sinaliza uma escalada de relevância do tema. A menção ao vírus Zika aparece no final da matéria, sem destaque na capa e de forma diluída em relação à dengue e ao chikungunya, como podemos ver neste trecho: “... especialistas acreditam que outro agente esteja por trás da atual situação em Pernambuco e investigam uma possível relação entre os casos com a infecção pelos vírus da dengue, chicungunha e zika durante a gestação" ${ }^{20}$.

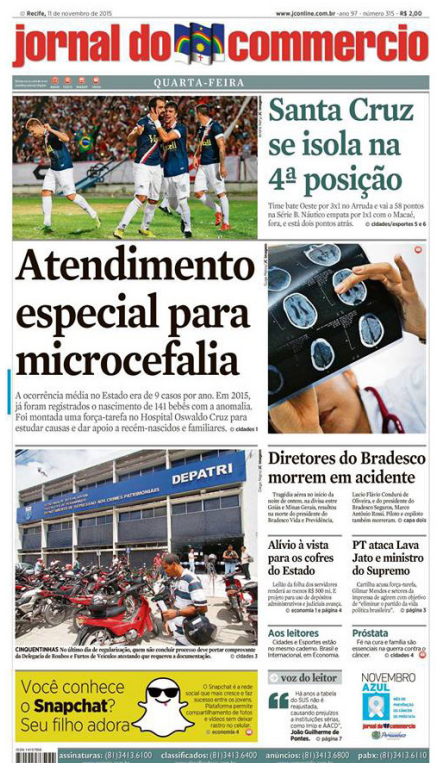

Figura 1 - Capa do Jornal do Commercio em 11 de novembro 
No mesmo dia, o MS convocou entrevista coletiva com a presença do ministro da Saúde e publicou nota informando que "está acompanhando a notificação e investigação dos casos de microcefalia em Pernambuco desde o dia 22 de outubro, quando foi notificado" ${ }^{21}$. Foi declarada Emergência em Saúde Pública de Importância Nacional, usando-se pela primeira vez o mecanismo criado em $2011^{22}$. O vírus Zika não foi mencionado na nota, porém, na cobertura da imprensa, a hipótese é amplamente apontada, como pode ser notado na cobertura do website G1: Sobre a hipótese que tem sido discutida pela comunidade médica, de que o aumento de casos de microcefalia poderia estar relacionado a infecções por zika vírus - vírus que foi identificado pela primeira vez no país em abril deste ano - os representantes do ministério afirmaram que ainda é precipitado atribuir o evento a essa causa ${ }^{23}$.
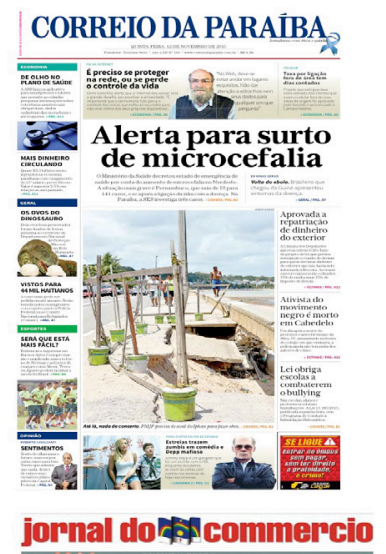

Casos de microcefalia deixam Pais em alerta

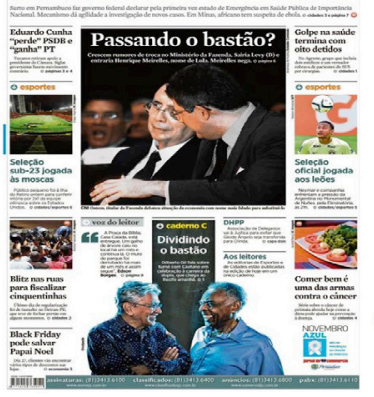

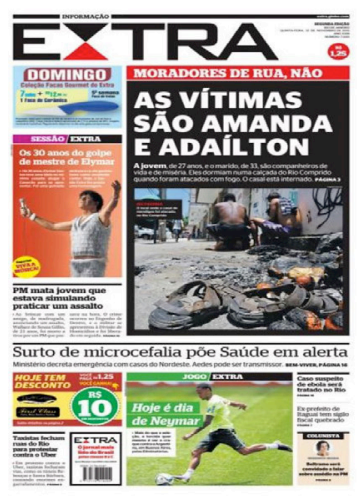

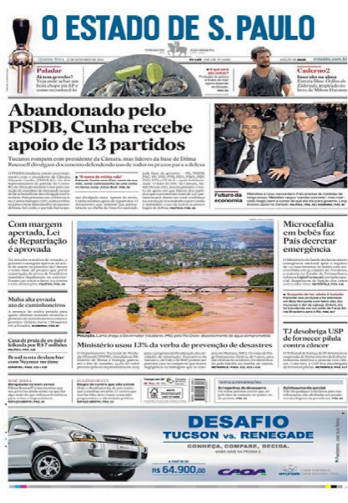

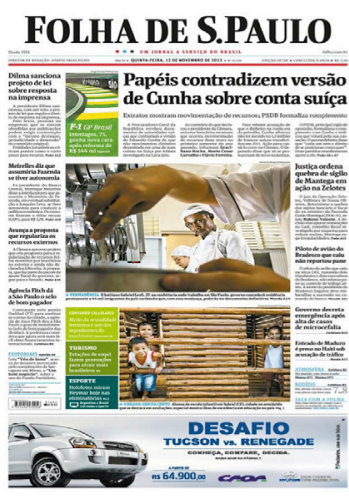

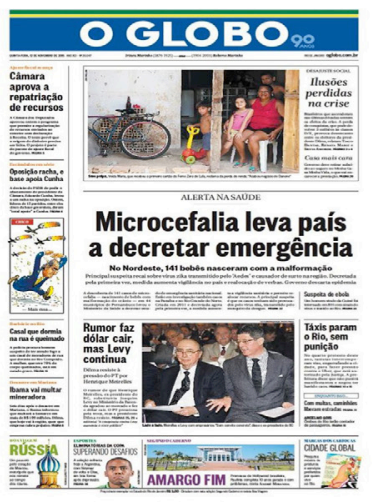

Figura 2 - Capas de jornais em 12 de novembro, dia seguinte à declaração de emergência nacional em saúde pública pelo MS

Durante a entrevista coletiva, o MS anunciou que publicaria periodicamente boletins epidemiológicos com o número de casos de microcefalia, o que sugere um entendimento de que a questão iria perdurar.

Um dia depois, surgiu uma polêmica com a declaração do diretor do departamento de Vigilância de Doenças Transmissíveis do MS, Cláudio Maierovitch, sugerindo o adiamento da gravidez em Pernambuco ${ }^{24}$. Houve forte repercussão nas redes sociais, com comentários contra e a favor. No dia seguinte, o MS publicou nota em que amenizava a recomendação de postergar a gestação²5. A nota informa que: "Não há uma recomendação do Ministério da Saúde para evitar a gravidez. As informações estão sendo divulgadas conforme o andamento das investigações. A decisão de uma gestação é individual de cada mulher e sua família." Na mesma data, surgiu nova polêmica motivada pela declaração do Ministro da Saúde de que "sexo é para amadores, gravidez é para profissionais"

Ainda em novembro, duas evidências técnicas relacionadas a possíveis causas dos casos de microcefalia ganhariam espaço na mídia. A primeira veio no dia 17 de novembro, quando o MS anunciou em entrevista coletiva e por meio de nota que a Fiocruz havia encontrado de forma inédita a presença do vírus Zika 
no líquido amniótico de duas gestantes da Paraíba cujos fetos, até então normais, passaram a apresentar redução do perímetro craniano em momento coincidente ao relato de sintomas do vírus Zika ${ }^{27}$. Na nota, que era destinada à divulgação do boletim epidemiológico de rotina e trazia essa informação no corpo do texto, sem destaque na chamada, era apontado que "ainda não é possível ter certeza sobre a causa para o aumento de microcefalia que tem sido registrado nos sete estados" e que "apesar de ser um achado científico importante para o entendimento da infecção por Zika vírus em humanos, os dados atuais não permitem correlacionar inequivocamente, de forma causal, a infecção pelo Zika com a microcefalia”. Já no diálogo dos representantes do MS com os jornalistas, durante entrevista coletiva, os termos adotados foram diferentes, expondo discursividades em conflito, com o uso de referências de que a correlação entre o vírus Zika e os casos de microcefalia era a "principal hipótese” 28 e "altamente provável”"29.

Em 24 de novembro, mais um boletim epidemiológico foi divulgado, reafirmando que "ainda não é possível ter certeza sobre a causa para o aumento de microcefalia", acrescentando-se que "o fato já foi comunicado à Organização Mundial de Saúde e à Organização Pan-Americana da Saúde”30.

A segunda evidência correlacionando o vírus Zika e os casos de microcefalia veio em 28 de novembro, quando o MS apontou que o vírus foi identificado na análise de um bebê com microcefalia que havia morrido após o parto, conduzida pelo Instituto Evandro Chagas, órgão do MS sediado no Pará. Desta vez, a informação não foi incluída em um boletim epidemiológico de rotina, mas foi alvo de um anúncio específico pelo MS. Foi aqui, pois, que o vírus emergente assumiu contornos de emergência em saúde pública. O próprio título da nota - "Ministério da Saúde confirma relação entre vírus Zika e microcefalia" - aponta uma mudança de tom, com a afirmativa cabal de que "a partir desse achado do bebê que veio a óbito, o Ministério da Saúde considera confirmada a relação entre o vírus e a ocorrência de microcefalia" ${ }^{31}$. $\mathrm{O}$ anúncio foi realizado em conjunto com a rotina de lançamento anual da campanha de controle do mosquito Aedes aegypti, considerado principal vetor do vírus Zika no país.

Novo boletim epidemiológico foi publicado no dia $30^{32}$. Além da atualização do número de casos de microcefalia, a nota acentuava a necessidade de "uma mobilização nacional no combate ao mosquito Aedes aegypti, responsável pela disseminação da dengue, zika e chikungunya".

Em 2 de dezembro, a Organização Pan-Americana da Saúde (OPAS) emitiu um alerta epidemiológico sobre o vírus Zika. No texto, o alerta é justificado pela "possível relação" do vírus com síndromes neurológicas e má formações congênitas ${ }^{33}$. Este foi o primeiro pronunciamento de um órgão de saúde internacional sobre o tema.

No dia 4, o MS anunciou a redução do parâmetro de perímetro craniano para diagnóstico clínico da microcefalia ${ }^{34}$, sem realizar entrevista coletiva ou publicar nota sobre o tema - o que chama a atenção por destoar do formato de divulgação adotado até aquele momento.

No dia 5 de dezembro, a presidenta da República lançou o Plano Nacional de Enfrentamento à Microcefalia em Recife, um dos locais mais afetados por casos de microcefalia no país ${ }^{35}$. A mudança de enunciador dá a dimensão da relevância do tema: é a autoridade máxima do país que se pronuncia.

Em 8 de dezembro, novo boletim epidemiológico foi publicado ${ }^{36}$, com as habituais atualizações dos números de casos de microcefalia.

No dia 9, a mídia notícia que o MS admitiu a relação entre o vírus Zika e os casos de Guillain-Barré, porém sem realizar entrevista coletiva ou emitir nota sobre o tema ${ }^{37}$. No dia 11, é anunciado o envio para os Estados de larvicida para o trabalho de controle do Aedes aegypti $i^{8}$. No dia 14, o MS lançou o "Protocolo de Atenção à Saúde e Resposta à Ocorrência de Microcefalia Relacionada à Infecção pelo Vírus Zika”, com diretrizes para o atendimento desde o pré-natal até o acompanhamento das crianças nascidas com microcefalia ${ }^{39}$.

No dia seguinte, novo boletim epidemiológico foi publicado ${ }^{40}$, atualizando o número de casos suspeitos de microcefalia. No dia 17, uma nota do MS desmentiu boatos em circulação nas redes sociais ${ }^{41}$, como a suposta correlação de vacinas vencidas com os casos de microcefalia. O aumento da capacidade de diagnóstico do vírus Zika nos laboratórios públicos foi tema de anúncio um dia depois ${ }^{42}$. 
No dia 22, o MS anunciou o reforço de ações de controle ao Aedes aegypti com agentes de saúde e alertou as pessoas que deixariam seus lares para festas de final de ano quanto à eliminação de criadouros do vetor ${ }^{43}$.

A autorização da Agência de Vigilância Sanitária (Anvisa) para comercialização da vacina contra dengue da empresa Sanofi-Pasteur foi anunciada em 28 de dezembro ${ }^{44}$. E, encerrando a linha do tempo em 2015, em 29 de dezembro foi divulgado o último boletim epidemiológico do ano, totalizando 2.975 casos suspeitos de microcefalia relacionada ao vírus Zika em recém-nascidos ${ }^{45}$.

\section{Observando a saúde na mídia: o vírus Zika em 2015}

Nossa análise aponta que o vírus Zika e temas relacionados foram assunto recorrente nas capas de jornais impressos em novembro e dezembro de 2015. Considerando-se as capas do período entre 11 de novembro - quando foi publicada a primeira, no Jornal do Commercio - e 31 de dezembro de 2015, o tema foi assunto em 187 capas, o que corresponde a 41\% do total de publicações dos mencionados jornais no período considerado. Neste cálculo foi computada apenas uma edição diária do jornal Zero Hora, que conta com edições diurna e noturna.

O espaço privilegiado da capa foi ocupado pelo vírus Zika e temas correlatos com diferentes intensidades, conforme mostra a Tabela 1. Apenas o jornal Super Notícia não fez menção ao Zika ou à microcefalia no período: suas quatro chamadas de capa foram referentes à dengue.

Tabela 1: Presença dos temas vírus Zika e correlatos nas capas de jornais

\begin{tabular}{l|l}
\hline Jornais analisados & Número de capas \\
\hline Jornal do Commercio & 39 \\
O Estado de São Paulo & 31 \\
Correio da Paraíba & 30 \\
O Globo & 29 \\
Folha de S.Paulo & 22 \\
Extra & 16 \\
Zero Hora & 11 \\
Correio & 5 \\
Supernotícia & 4
\end{tabular}

Fonte: Tabela de elaboração própria.

Frente aos dados, a primeira observação é de forte agendamento do tema, com importante presença nas capas de jornais. No entanto, houve uma flagrante diferença entre os veículos, quanto à ocupação desse espaço com o tema, sendo que os quatro jornais com maior número de ocorrências responderam por $69 \%$ do total de ocorrências da temática nas capas.

Em relação aos marcos temporais de início da presença do tema nas capas, os seis veículos que lideram o ranking iniciaram simultaneamente as publicações em 11 e 12 de novembro, quando o MS anunciou a situação de emergência em saúde pública. 
Tabela 2: Data de início da presença dos termos vírus Zika e correlatos nas capas de jornais

\begin{tabular}{l|l}
\hline Data de início da presença & Jornais analisados \\
\hline $11 /$ nov/2015 & Jornal do Commercio \\
$12 /$ nov & Correio da Paraíba, Extra, Folha de S. Paulo, O Estado de São Paulo, O Globo \\
$30 /$ nov & Zero Hora \\
$01 /$ dez & Correio \\
$20 /$ dez & Supernotícia
\end{tabular}

Fonte: Tabela de elaboração própria.

A figura 3 correlaciona alguns dos tópicos da linha do tempo à presença do tema do vírus Zika e correlatos nas capas dos jornais analisados. Os dias considerados na análise foram dispostos de forma circular, a partir de $1^{\circ}$ de novembro até 31 de dezembro. Para cada dia, é indicada a quantidade de capas de jornal que abordam o tema, representada pela escala de círculos concêntricos a partir do núcleo. O total de jornais foi sinalizado em azul, enquanto os jornais locais publicados nos estados com maior número de casos de microcefalia - Bahia, Paraíba e Pernambuco - foram sinalizados em laranja. As esferas nas cores verde e rosa sinalizam a ênfase do discurso presente nas notícias, que identificamos como referências a medo (verde) e a risco (rosa). Cada esfera corresponde a uma capa de jornal.

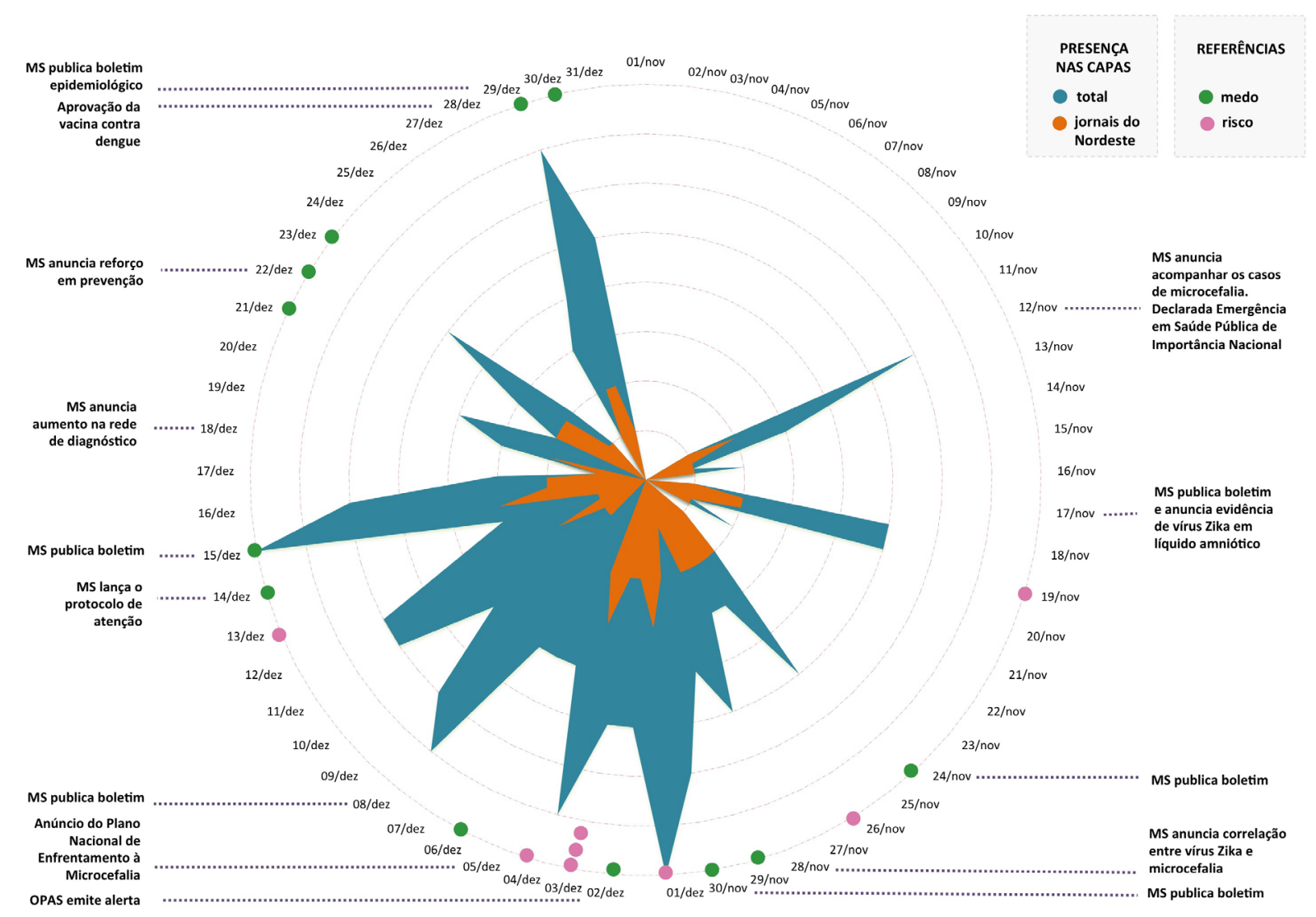

Figura 3 - Presença dos temas vírus Zika e correlatos em capas de jornais impressos: associação a fatos da linha do tempo e à ocorrência de referências a medo e risco.

Fonte: Diagrama de elaboração própria. 
Observada a figura, chama a atenção o silêncio sobre o tema entre $1^{\circ}$ e 10 de novembro. Notamos dois picos intensos de notícias no dia 12 de novembro e nos dias 18 e 19, correspondendo, respectivamente, ao anúncio da situação de emergência em saúde pública pelo MS e pelo comunicado da evidência científica da presença do vírus em líquido amniótico relacionado a casos de microcefalia. A partir de 24 de novembro até 16 de dezembro, observamos uma presença intensa do tema, com uma variação em no mínimo três capas de jornais diariamente e picos de presença nas capas de todos os nove jornais analisados.

A presença do tema nas capas não apresentou discrepância relevante do ponto de vista regional, com os jornais da Bahia, Paraíba e Pernambuco acompanhando, de forma geral, os picos de visibilidade do tema observados no conjunto analisado.

No que se refere à correlação com os fatos elencados na linha do tempo, observamos que muitas vezes o noticiário acompanha os anúncios do MS, o que aponta para um forte efeito de agendamento, especialmente no dia seguinte aos anúncios. Porém, também é observada a presença de notícias desconectadas daquilo que foi feito circular pelo governo, resultantes de abordagens dos próprios veículos.

Quanto à presença de referências explícitas a medo e a risco, do ponto de vista da linha do tempo, observamos que a maior concentração de referências a risco, está associada ao anúncio de alerta de saúde pública realizado pela OPAS, com presença simultânea em capas de três jornais - portanto, no momento em que um enunciador externo entra em cena. Já o tema do medo é mais disperso do ponto de vista da linha do tempo, sem a ocorrência de menções simultâneas na mesma data.

Já do ponto de vista da distribuição por veículo, apresentada na Quadro 1, notamos que há uma concentração expressiva das referências a medo e a risco no Correio da Paraíba. Em relação aos demais veículos, a menção a risco foi mais frequente em $O$ Globo, ao passo que não foram observadas referências a medo nas capas deste veículo no período. No sentido contrário, no jornal Folha de S.Paulo foram notadas apenas referências a medo, com ausência de referências a risco.

Quadro 1: Presença de referências a medo e a risco relacionadas ao tema do vírus Zika e correlatos nas capas de jornais

\begin{tabular}{|c|c|c|c|c|}
\hline \multirow[t]{2}{*}{ Jornais analisados } & \multicolumn{2}{|c|}{ Referências a medo } & \multicolumn{2}{|c|}{ Referências a risco } \\
\hline & $\begin{array}{l}\text { Ocorrência } \\
\text { por jornal }\end{array}$ & $\begin{array}{c}\text { Total de ocorrências no } \\
\text { período } \\
\text { (todos os jornais) }\end{array}$ & $\begin{array}{l}\text { Ocorrência por } \\
\text { jornal }\end{array}$ & $\begin{array}{c}\text { Total de ocorrências } \\
\text { no período } \\
\text { (todos os jornais) }\end{array}$ \\
\hline Correio & 2 & \multirow{9}{*}{16} & 0 & \multirow{9}{*}{10} \\
\hline Correio da Paraíba & 4 & & 4 & \\
\hline Extra & 2 & & 1 & \\
\hline Folha de S. Paulo & 3 & & 0 & \\
\hline Jornal do Commercio & 3 & & 1 & \\
\hline O Estado de São Paulo & 2 & & 1 & \\
\hline O Globo & 0 & & 3 & \\
\hline Supernotícia & 0 & & 0 & \\
\hline Zero Hora & 0 & & 0 & \\
\hline
\end{tabular}

Fonte: Quadro de elaboração própria.

Reiterando o afirmado antes, o olhar lançado sobre a presença desses dois referentes - medo e risco - nas capas analisadas foi tão somente quantitativo, não sendo contabilizadas outras formas de constituir seu sentido, além da referência explícita. A decisão de olhar a presença do termo "risco" se deveu ao fato de que ele, estando subjacente ou explícito em praticamente toda a comunicação que se faz no campo da saúde, na 
atual epidemia ele próprio passou a ser questionado, como veremos na sequência deste artigo. $\mathrm{O}$ referente "medo" foi incluído por sua estreita relação de sentido, por intertextos vários, com o risco.

\section{Reflexões sobre a relação entre comunicação e saúde}

Muitas reflexões podem emanar do que foi apresentado anteriormente. Optamos por retomar, a partir da abordagem midiática das epidemias associadas de Zika e microcefalia e sua associação com os informes oficiais, questões que têm sido recorrentes entre os que pensam criticamente a relação entre comunicação e saúde. As questões estão propostas, sugeridas, sem pretender oferecer respostas, apenas contribuir para o necessário debate.

1. Silêncios e silenciamentos. O vírus Zika é um assunto novo, mas a microcefalia não. Pelo contraste, a superexposição recente da microcefalia evidencia o quanto, até então, o assunto era altamente silenciado, tanto pela mídia quanto pelo governo. Podemos, então, perguntar: qual a razão desse silêncio anterior? Poderíamos cogitar uma relação entre esse silêncio e a condição econômica e social das pessoas e das regiões mais afetadas? Indo um pouco além: se a saúde falasse sobre essas e outras doenças "esquecidas", fora de um surto epidêmico, a mídia também falaria? Ou por sua lógica de noticiabilidade, vinculada à de espetacularidade, não se interessaria por essas doenças? Na mesma linha de reflexão: se o vírus Zika e os casos de microcefalia não tivessem surgido inicialmente no Nordeste, mas no eixo Rio-São Paulo, a atenção e o tratamento da mídia teriam sido diferentes? Teriam despertado antes a atenção jornalística?

2. Narrativas de sofrimento. Páginas e minutos plenos de mães com seus bebês atingidos pela microcefalia, expondo suas narrativas de sofrimento. O que podemos refletir sobre a exploração do drama humano na mídia brasileira quando se fala da saúde? Interesse genuíno de fazer falar os mais atingidos, ou ainda a lógica da espetacularidade?

3. Responsabilização e estigmatização. A declaração de uma gestante de Vertentes, Pernambuco, sobre a causa da microcefalia em seu bebê - "foi alguma coisa que eu fiz? algo que eu comi e fez mal?", capa da Folha de S.Paulo em 18 de novembro ${ }^{46}$ - coloca em cena no mínimo duas discussões na medida em que realça, simultaneamente, o desconhecimento da mãe e sua condição de nordestina e pobre. Uma, a da prática corrente na Saúde Pública de responsabilização da vítima pelo que lhe aconteceu, eximindo responsabilidades outras, inclusive e fortemente do Estado. A mídia, em suas escolhas do que destacar, endossa e amplifica largamente essa prática. A ignorância seria parte consistente da situação que aquela mãe estava vivendo. Está doente porque é ignorante, eis a mensagem. A outra discussão coloca em cena a equidade em saúde, entendida como a justa oportunidade de um indivíduo atingir todo o seu potencial de saúde e, mais pragmaticamente, que ninguém esteja em desvantagem para atingir este potencial, se isto puder ser evitado ${ }^{47}$. $\mathrm{O}$ drama da microcefalia vem atingindo principalmente as pessoas negligenciadas pelos poderes públicos. Algumas perguntas emergem: a mídia apenas reflete a ausência de equidade que se verifica na saúde? Ou em seus dispositivos acentua e amplia a desigualdade social, ao simbolicamente associar a doença a uma presumível ignorância? A exposição da tragédia e de suas vítimas poderia contribuir de algum modo para a minimização das iniquidades sociais? A visibilidade das capas de jornais interessa aos visibilizados? Produz algum efeito em suas vidas? A quem ou a que serve esse dispositivo midiático?

4. As limitações da ciência e a volúpia midiática. O conhecimento científico sobre o vírus Zika é limitado, o que coloca um desafio para os cientistas e médicos sobre o que e quando comunicar e, ao mesmo tempo, um desafio para os profissionais de comunicação sobre como reportar a incerteza. Entre os extremos da cobrança acusatória e das expectativas exageradas, entra em pauta a questão mais básica de epistemologia científica: a premissa de que a ciência é uma construção. Neste momento em que a ciência tem sua legitimidade colocada na berlinda, qual controle social da ciência e da saúde é possível? Indo além: se a mídia se apresenta como mediadora entre o conhecimento científico e a sociedade, de que maneira vem exercendo esse papel? Pressionando a ciência por respostas que ainda não existem? Buscando culpados 
numa abordagem denuncista? Extraindo certezas onde só pairam hipóteses? Sacrificando a premissa mais básica de apuração jornalística para divulgar notícias que alimentam boatos?

5. Espaço para o contraditório. O noticiário da ciência geralmente é pautado em fontes únicas, o que é coerente com uma visão única da ciência e reforça o imaginário quanto ao seu caráter de miraculismo ${ }^{48}$. Estamos, porém, num momento de inversão, já que as incertezas sobre o tema colocam o contraditório no olho do furacão, com a contraposição de fontes ganhando espaço, inclusive dentro das instituições de saúde. O que este fenômeno permite pensar sobre o cotidiano da cobertura midiática em ciência e saúde? A prática de mobilizar diferentes pontos de vista vai perdurar depois de passada a crise da epidemia? Ou esta é uma prática reservada aos temas polêmicos? A apuração jornalística mais cuidadosa, ouvindo fontes variadas, é uma prática muito presente em situações de incerteza como esta e poderia representar um ganho duradouro para uma cobertura jornalística que contribuísse efetivamente para o papel da mídia na mediação entre ciência e sociedade. Uma pergunta seria o que e como poderíamos fazer algo neste sentido, a partir do próprio campo científico. Mas podemos também perguntar: interessa ao campo científico essa prática midiática de dar espaço ao contraditório? Não tem a própria ciência se apresentado como um espaço adverso a uma ecologia de saberes ${ }^{49}$ ?

6. Medo e risco. As palavras 'medo' e 'risco' perpassaram o noticiário, por diferentes vozes e modalidades do dizer. O debate sobre o 'risco' ganhou muitos e novos contornos.

No caso do vírus Zika, o risco está sendo tratado com um acentuado grau de incerteza Considerando-se o risco pela sua relação com a mudança de atitude no presente na tentativa de se evitar uma possibilidade de futuro, quais os desafios de um ambiente em que há incerteza quanto ao próprio risco? Qual o papel da comunicação nesses casos?

7. Os discursos não autorizados. Boatarias com informações sem qualquer fundamento, como a correlação da microcefalia com vacinas vencidas, ganharam a internet, as redes sociais, com viralidade acentuada. Quem tem a ganhar com isto? Quais são os interesses que estão por trás de informações que desmoralizam a saúde pública? E mais: por que, nestas situações, não se fala em cybercrime?

8. Oportunidades de negócios. Inseticidas, repelentes, testes rápidos e outras tantas oportunidades de negócio, que já existiam com a dengue, se acentuaram. A antiga discussão sobre o financiamento dos veículos de imprensa coloca mais uma vez em xeque a influência dos anunciantes de espaços publicitários sobre os espaços jornalísticos dos veículos de comunicação. Quais os interesses da mídia ao dar espaço para notícias que claramente estão situadas no campo do consumo? E que capacidade crítica têm os jornalistas a esse respeito?

9. Vozes em cena. Pensando a comunicação como um mercado simbólico, em que ocorre a disputa de diferentes forças ${ }^{49}$, temos visto na mídia, altissonantes, as vozes da ciência, dos governos. Com uma presença ínfima e sempre para ilustrar a das demais, encontramos as vozes dos familiares de bebês com microcefalia ou de pacientes com Guillain-Barré. A abordagem tradicional midiática, que convoca a fala do povo para legitimar a sua própria, está ausente em temas controversos como o do Zika/microcefalia, ou presente numa proporção muito reduzida. Podemos perguntar: por que isto vem ocorrendo? Estaria relacionado à incerteza sobre o risco, aludida acima? Ou decorre uma desqualificação a priori das vozes populares? Considerando que essa desqualificação ocorre também no campo da saúde e que não é um fenômeno específico da epidemia do vírus Zika, mas se constitui historicamente, sendo estruturante inclusive da maioria das práticas de comunicação em e na saúde, perguntamos: o que nos cabe fazer, nesse momento histórico que a Saúde Pública atravessa? Como nós, pesquisadores, jornalistas, comunicólogos, profissionais da palavra, poderíamos intervir produtivamente nessas velhas e rançosas práticas, compartilhadas pelos campos midiáticos e sanitários, aproveitando o momento de crise para avançar na direção de uma comunicação que favoreça e fortaleça uma saúde mais de acordo com os princípios do SUS? 
Uma comunicação marcada pela universalidade, porém com equidade, em que todas as vozes e saberes possam ser acolhidos e considerados?

Estas provocações iniciais ficam como um convite para os que fazem, os que pensam ou simplesmente aqueles que se interessam pelo campo da comunicação, particularmente em sua interface com o campo da saúde. O que acompanhamos sobre o tema do vírus Zika em 2015 terá sido muito barulho por nada? Briga contra moinhos de vento? Apenas o começo? O tempo dirá. O que já podemos dizer é que as emergências do vírus Zika aportam uma oportunidade ímpar para observar a saúde na mídia brasileira. Continuaremos observando.

\section{Referências}

1. Associação Nacional de Jornais [Internet]. Maiores Jornais do Brasil. Disponível em: www.anj.org.br/ maiores-jornais-do-brasil.

2. Meio \& Mensagem [Internet]. Portfólio de vendas, Jornal da Paraíba. Disponível em: http:// portfoliodeveiculos.meioemensagem.com.br/portfolio/veiculos/CORREIO+DA+PARA\%25C3\%258D BA/14383/home;jsessionid=BE9738ABE909906707366273EA9F0E1D.

3. Zanluca C, Melo VCA, Mosimann ALP, Santos GIV, Santos CND, Luz K. First report of autochthonous transmission of Zika virus in Brazil. Mem. Inst. Oswaldo Cruz. 2015 June; 110(4):569-572.

4. Campos GS, Bandeira AC, Sardi SI. Zika virus outbreak, Bahia, Brazil. Emerg Infect Dis. 2015 Oct, 21(10):5.

5. G1. Doença sem diagnóstico assusta moradores de Camaçari: 'angustiante'. Publicado em: 24 mar. 2015. Disponível em: http://g1.globo.com/bahia/noticia/2015/03/doenca-sem-diagnostico-assusta-moradoresde-camacari-angustiante.html. Acesso em: 23 dez. 2015.

6. G1. Doença misteriosa de Camaçari pode ser roséola ou parvorírus-B19. Publicado em: 25 mar. 2015. Disponível em: http://g1.globo.com/bahia/noticia/2015/03/doenca-misteriosa-de-camacari-pode-serroseola-ou-parvorirus-b19.html. Acesso em: $23 \mathrm{dez} .2015$.

7. G1. Órgãos de saúde investigam doença com manchas vermelhas na Paraíba. Publicado em: 28 abr. 2015. Disponível: http://g1.globo.com/pb/paraiba/noticia/2015/04/orgaos-de-saude-investigam-doencacom-manchas-vermelhas-na-paraiba.html. Acesso em: 23 dez. 2015.

8. Ministério da Saúde [Internet]. SVS monitora casos de doença exantemática no Nordeste. Publicado em: 29 abr. 2015. Disponível em: http://portalsaude.saude.gov.br/index.php/o-ministerio/principal/ secretarias/svs/noticias-svs/17524-svs-monitora-casos-de-doenca-exantematica-no-nordeste. Acesso em: 23 dez. 2015.

9. Universidade Federal da Bahia [Internet]. Pesquisadores da UFBA identificam vírus que provoca doença semelhante à dengue. Publicado em: 29 abr. 2015. Disponível em: https://www.ufba.br/noticias/ pesquisadores-da-ufba-identificam-v\%C3\%ADrus-que-provoca-doença-semelhante-à-dengue. Acesso em: 23 dez. 2015.

10. Jornal do Commercio. Chioro falará sobre Zika só na próxima semana. Disponível em: http://jc.ne10.uol. com.br/blogs/maissaude/2015/04/30/chioro-falara-sobre-zika-so-na-proxima-semana/.

11. Ministério da Saúde [Internet]. Confirmação do Zika Vírus no Brasil. Publicado em: 14 maio 2015. Disponível em: http://portalsaude.saude.gov.br/index.php/o-ministerio/principal/secretarias/ svs/noticias-svs/17702-confirmacao-do-zika-virus-no-brasil. Acesso em: 23 dez. 2015.

12. G1. Ministério da Saúde confirma 8 casos de zika vírus no RN e 8 na BA. Disponível em: http://g1.globo. com/bemestar/noticia/2015/05/ministerio-da-saude-confirma-16-casos-de-zika-virus-no-brasil.html. Acesso em: 23 dez. 2015.

13. Rede TV [Internet]. Ministro da Saúde diz que Brasil vive 'tecnicamente uma epidemia de dengue'. Disponível em: http://www.redetv.uol.com.br/jornalismo/cidades/ministro-da-saude-diz-que-brasil-vivetecnicamente-uma-epidemia-de-dengue.

14. A Tarde [Internet]. Guillain-Barré: Sesab confirma 55 casos e uma morte na Bahia. Disponível em: http://atarde.uol.com.br/bahia/noticias/1695110-guillain-barre-sesab-confirma-55-casos-e-uma-mortena-bahia. Acesso em: 23 dez. 2015. 
15. Folha de S. Paulo [Internet]. Casos de doença rara e paralisante se espalham pelo Nordeste. Disponível em: http://www1.folha.uol.com.br/cotidiano/2015/07/1659028-casos-de-doenca-rara-e-paralisante-seespalham-pelo-nordeste.shtml. Acesso em: 23 dez. 2015.

16. Associação de Obstetrícia e Ginecologia do Estado de São Paulo [Internet]. Comunicado médico: surto de Microcefalia no Nordeste do Brasil. Disponível em: http://www.sogesp.com.br/lib/media/pdf/ comunicado-medico-um-surto-de-microcefalia.pdf.

17. Secretaria de Saúde de Mato Grosso do Sul [Internet]. Zika vírus pode estar ligado a casos de microcefalia em recém-nascidos. Disponível em: http://www.noticias.ms.gov.br/zika-virus-pode-estarligado-a-casos-de-microcefalia-em-recem-nascidos.

18. Jornal do Commercio [Internet]. Notificação de casos de microcefalia agora é obrigatória em Pernambuco. Disponível em: http://jconline.ne10.uol.com.br/canal/cidades/saude/noticia/2015/11/04/ notificacao-de-casos-de-microcefalia-agora-e-obrigatoria-em-pernambuco--206433.php.

19. Jornal da Paraíba [Internet]. Saúde de CG investiga risco do Zika Vírus causar microcefalia. Disponível em: http://www.jornaldaparaiba.com.br/cidades/noticia/161166 saude-de-cg-investiga-risco-do--zikavirus-causar-microcefalia.

20. Jornal do Commercio. Atendimento especial para microcefalia. 2015 nov 11. Cidades, 1.

21. Ministério da Saúde [Internet]. Ministério da Saúde investiga aumento de casos de microcefalia em Pernambuco. Disponível em: http://portalsaude.saude.gov.br/index.php/cidadao/principal/agenciasaude/20629-ministerio-da-saude-investiga-aumento-de-casos-de-microcefalia-em-pernambuco.

22. Decreto $n^{\circ}$. 7.616, de 17 de novembro de 2011. Disponível em: http://www.planalto.gov.br/ccivil 03/ Ato2011-2014/2011/Decreto/D7616.htm.

23. G1. Governo declara emergência em saúde por casos de microcefalia. Disponível em: http://g1.globo. com/bemestar/noticia/2015/11/ministerio-da-saude-investiga-casos-de-microcefalia-no-nordeste.html.

24. Estado de São Paulo [Internet]. Diretor do Ministério da Saúde aconselha que mulheres de Pernambuco adiem gravidez. Disponível em: http://saude.estadao.com.br/noticias/geral,diretor-do-ministerio-dasaude-aconselha-mulheres-de-pe-a-adiar-gravidez, 10000001872.

25. Ministério da Saúde [Internet]. Ministério dá orientações às gestantes sobre os casos de microcefalia. Disponível em: http://portalsaude.saude.gov.br/index.php/cidadao/principal/agencia-saude/20692orientacoes-as-gestantes-sobre-os-casos-de-microcefalia.

26. Estado de São Paulo [Internet]. "Sexo é para amadores, gravidez é para profissionais", diz ministro da Saúde. Disponível em: http://saude.estadao.com.br/noticias/geral,sexo-e-para-amadores-gravidez-epara-profissionais-diz-ministro-da-saude, 10000002325.

27. Ministério da Saúde [Internet]. Ministério da Saúde divulga boletim epidemiológico. Disponível em: http://portalsaude.saude.gov.br/index.php/cidadao/principal/agencia-saude/20805-ministerio-da-saudedivulga-boletim-epidemiologico.

28. G1. Zika vírus é 'principal hipótese' para aumento de microcefalia, diz Saúde. Disponível em: http:// g1.globo.com/bemestar/noticia/2015/11/virus-zika-e-principal-hipotese-para-aumento-de-microcefaliadiz-saude.html.

29. Uol. Pela primeira vez no mundo, zika vírus é relacionado a microcefalia em bebê. Disponível em: http://noticias.uol.com.br/saude/ultimas-noticias/redacao/2015/11/17/pela-primeira-vez-zika-virus-erelacionado-a-microcefalia-de-bebes.htm.

30. Ministério da Saúde [Internet]. Ministério divulga boletim epidemiológico. Disponível em: http:// portalsaude.saude.gov.br/index.php/cidadao/principal/agencia-saude/20925-ministerio-divulga-boletimepidemiologico.

31. Ministério da Saúde [Internet]. Ministério da Saúde confirma relação entre vírus Zika e microcefalia. Disponível em: http://portalsaude.saude.gov.br/index.php/cidadao/principal/agencia-saude/21014ministerio-da-saude-confirma-relacao-entre-virus-zika-e-microcefalia.

32. Ministério da Saúde [Internet]. Ministério da Saúde divulga novos dados de microcefalia. Disponível em: http://portalsaude.saude.gov.br/index.php/cidadao/principal/agencia-saude/21019-ministerio-da-saudedivulga-novos-dados-de-microcefalia. 
33. Panmerican Health Organization [Internet]. Epidemiological Alert: Neurological syndrome, congenital malformations, and Zika virus infection. Implications for public health in the Americas. Disponível em: http://www.paho.org/hq/index.php?option=com docman\&task=doc download\&Itemid=\&gid=32405\&la ng=en.

34. O Globo [Internet]. Governo muda critério para definir microcefalia. Disponível em: http://oglobo.globo. com/sociedade/saude/governo-muda-criterio-para-definir-microcefalia-18218137.

35. Ministério da Saúde [Internet]. Governo Federal lança plano de enfrentamento à microcefalia. Disponível em: http://portalsaude.saude.gov.br/index.php/cidadao/principal/agencia-saude/21108-governo-federallanca-plano-de-enfrentamento-a-microcefalia.

36. Ministério da Saúde [Internet]. Ministério da Saúde divulga novos casos de microcefalia. Disponível em: http://portalsaude.saude.gov.br/index.php/cidadao/principal/agencia-saude/21164-ministerio-da-saudedivulga-novos-casos-de-microcefalia.

37. O Globo [Internet]. Governo confirma relação entre Guillain-Barré e vírus zika. Disponível em: http:// oglobo.globo.com/sociedade/saude/governo-confirma-relacao-entre-guillain-barre-virus-zika-18257364.

38. Ministério da Saúde [Internet]. Saúde envia larvicida para tratar 9 bilhões de litros de água. Disponível em: http://portalsaude.saude.gov.br/index.php/cidadao/principal/agencia-saude/21217-saude-envialarvicida-para-tratar-9-bilhoes-de-litros-de-agua.

39. Ministério da Saúde [Internet]. Ministério lança protocolo de Atenção à Saúde para Microcefalia. Disponível em: http://portalsaude.saude.gov.br/index.php/cidadao/principal/agencia-saude/21241saude-lanca-protocolo-de-atencao-a-saude-para-microcefalia.

40. Ministério da Saúde [Internet]. Ministério da Saúde atualiza números de microcefalia relacionados ao Zika. Disponível em: http://portalsaude.saude.gov.br/index.php/cidadao/principal/agencia-saude/21254ministerio-da-saude-atualiza-numeros-de-microcefalia-relacionados-ao-zika.

41. Ministério da Saúde [Internet]. Ministério esclarece boatos sobre vírus Zika. Disponível em: http:// portalsaude.saude.gov.br/index.php/cidadao/principal/agencia-saude/21291-ministerio-esclarece-boatossobre-virus-zika.

42. Ministério da Saúde [Internet]. Brasil já conta com 16 laboratórios para diagnosticar Zika. Disponível em: http://portalsaude.saude.gov.br/index.php/cidadao/principal/agencia-saude/21306-brasil-ja-contacom-16-laboratorios-para-diagnosticar-zika.

43. Ministério da Saúde [Internet]. Ministério da Saúde alerta os viajantes para eliminação dos criadouros. Disponível em: http://portalsaude.saude.gov.br/index.php/cidadao/principal/agencia-saude/21365ministerio-da-saude-alerta-viajantes-para-eliminacao-dos-criadouros.

44. Ministério da Saúde [Internet]. Dengue: nota sobre o registro da primeira vacina. Disponível em: http:// portalsaude.saude.gov.br/index.php/cidadao/principal/agencia-saude/21447-nota-sobre-o-registro-daprimeira-vacina.

45. Ministério da Saúde [Internet]. Saúde divulga dados atualizados de microcefalia. Disponível em: http:// portalsaude.saude.gov.br/index.php/cidadao/principal/agencia-saude/21459-saude-divulga-dadosatualizados-de-microcefalia.

46. Folha de S. Paulo [Internet]. Pensei que fosse efeito de algo que comi, diz mãe de bebê com microcefalia. Disponível em: http://www1.folha.uol.com.br/cotidiano/2015/11/1707846-pensei-quefosse-efeito-de-algo-que-comi-diz-mae-de-bebe-com-microcefalia.shtml.

47. Whitehead M. The Concept and Principles of Equity and Health. Copenhagen: World Health Organization / Regional Office for Europe; 1990.

48. Castelfranchi Y. Para além da tradução: o jornalismo científico crítico na teoria e na prática. In: Massarani $\mathrm{L}$, Polino C, organizadores. Los desafíos y la evaluación del periodismo cientifico em Iberomerica. Anais das Jornadas Iberoamericanas sobre la ciencia en los medios masivos; 2007 jul 30 - ago 3; Santa Cruz de la Sierra, Bolívia. Santa Cruz de la Sierra: AECI, RICYT, CYTED, SciDevNet, OEA; 2008. p.10-20.

49. Santos, B. S.A gramática do tempo: para uma nova cultura política. São Paulo: Cortez, 2010.

50. Bourdieu P. O poder simbólico. Rio de Janeiro: Ed. Bertrand Brasil,2011. 